\title{
Growth Suppression of Human Colorectal Cancer Cells with Mutated $K R A S$ by 3-Deaza-cytarabine in 3D Floating Culture
}

\author{
HAO LUO ${ }^{1 *}$, KENSUKE NISHI $^{1,2^{*}}$, SHUHEI ISHIKURA ${ }^{1,3}$, ANTHONY SWAIN $^{1}$, NAOYUKI MORISHIGE ${ }^{1,4}$, \\ RYO YAZAKI ${ }^{5}$, TAKASHI OHSHIMA ${ }^{5}$, SENJI SHIRASAWA ${ }^{1,3}$ and TOSHIYUKI TSUNODA ${ }^{1,3}$ \\ Departments of ${ }^{1}$ Cell Biology, and ${ }^{2}$ Otorhinolaryngology, Faculty of Medicine, and \\ ${ }^{3}$ Central Research Institute for Advanced Molecular Medicine, Fukuoka University, Fukuoka, Japan; \\ ${ }^{4}$ Ohshima Eye Hospital, Fukuoka, Japan; \\ ${ }^{5}$ Graduate School of Pharmaceutical Sciences, Kyushu University, Fukuoka, Japan
}

\begin{abstract}
Background/Aim: During screening for compounds that selectively suppress growth of human colorectal cancer (CRC) spheroids with mutant (mt) KRAS, the uridine analogue, 5-bromouridine ( $\mathrm{BrUrd})$ was identified and its derivatives were explored. Materials and Methods: DNA incorporation in twodimensional (2D) and three-dimensional floating (3DF) cultures was examined with the uridine analogue, 5-ethynyl2'-deoxyuridine (EdU). The area of HKe3 CRC spheroids expressing wild type (wt) KRAS (HKe3-wtKRAS) and mtKRAS (HKe3-mtKRAS) were measured in $3 D F$ culture with $11 \mathrm{BrUrd}$ derivatives. Results: EdU was strongly incorporated into newly-synthesized DNA from HKe3-mtKRAS cells compared to HKe3-wtKRAS in 2D and 3DF culture. 3-Deaza-cytarabine, which has properties of BrUrd and cytidine, was the most effective inhibitor of HKe3-mtKRAS spheroids with the least toxicity to HKe3-wtKRAS. Growth suppression of 3-deazacytarabine was stronger than cytarabine in $2 D$ culture, and toxicity was lower than gemcitabine in long-term $3 D F$ culture. Conclusion: 3-Deaza-cytarabine exhibits properties useful for the treatment of CRC patients with mtKRAS.
\end{abstract}

Anticancer nucleosides include several analogues which fall into the categories of physiological pyrimidine and purine nucleosides. Pyrimidine analogues are further

\footnotetext{
*These Authors contributed equally to this study.

Correspondence to: Toshiyuki Tsunoda, MD, Ph.D., Department of Cell Biology, Faculty of Medicine Fukuoka University, 7-45-1 Nanakuma, Jonan-ku, Fukuoka 814-0180, Japan. Tel: +81 928011011, Fax: +81 928643865, e-mail: tsunoda@fukuoka-u.ac.jp

Key Words: Colorectal cancer, KRAS, 3D floating culture, nucleoside analogue, 5-bromouridine (BrUrd), 4-Amino-1-( $\beta$-Darabinofuranosyl)-2(1H)-pyridinone (3-deaza cytarabine).
}

categorised into cytidine and uridine (or thymidine) analogues (1). Several pyrimidine analogues were synthesized and evaluated (2), and the first of these analogues to be approved by the US Food and Drug Administration (FDA) was the cytidine analogue, cytosine $\beta$-D-arabinofuranoside hydrochloride (cytarabine), that was approved in 1969 for the treatment of acute leukemia (3). In 1996, the FDA approved another cytidine analogue called 2',2'-difluorodeoxycytidine (gemcitabine) (4). Gemcitabine has more favourable pharmacokinetic properties including greater solubility and lower toxicity to normal cells than cytarabine both in vitro and in vivo and has been used for the treatment of patients with solid tumours, including pancreatic cancers, lung cancers and colorectal cancers (CRCs) $(5,6)$. In these tumours a critically involved signalling pathway associated with oncogenic mutations in the Kirsten rat sarcoma viral oncogene homologue (KRAS) gene was identified (7). Furthermore, clinical studies have shown that patients with mutated (mt) KRAS show a worse response to gemcitabinebased therapy than those with wild-type (wt) KRAS (8). However, drugs selectively targeting oncogenic KRAS have not yet been clinically developed (9). Recently, we established a three-dimensional floating (3DF) culture system to preliminary screen chemical libraries which inhibit mtKRAS-mediated signaling (10). As a result, the uridine analogue, 5-bromouridine (BrUrd), was identified as a novel molecule that may be able to selectively target HKe3-mtKRAS spheroids and may exhibit low level toxicity to wtKRAS spheroids.

In order to determine the effects of 11 BrUrd derivatives in CRC with mtKRAS in vitro, 3DF culture was performed using the HKe3 cells overexpressing wtKRAS (HKe3wtKRAS) and mtKRAS (HKe3-mtKRAS) (10). Our results suggest that 3-deaza-cytrabine may be an effective treatment for human colorectal cancer. 
Table I. List of BrUrd derivatives.

\begin{tabular}{|c|c|c|c|c|c|}
\hline & Name & Structure & Formula & MW & \begin{tabular}{|l|} 
Distance \\
\end{tabular} \\
\hline 0 & 5-Bromour idine & & $\mathrm{C}_{9} \mathrm{H}_{11} \mathrm{BrN}_{2} \mathrm{O}_{6}$ & 323.10 & 0 \\
\hline 1 & $\begin{array}{l}\text { 5-Bromo-2' - } \\
\text { deoxyur idine }\end{array}$ & & $\mathrm{C}_{9} \mathrm{H}_{11} \mathrm{BrN}_{2} \mathrm{O}_{5}$ & 307.10 & 0.111 \\
\hline 2 & NPD7328 & & $\mathrm{C}_{9} \mathrm{H}_{11} \mathrm{FN}_{2} \mathrm{O}_{5}$ & 246. 20 & 0.288 \\
\hline 3 & NPD5460 & & $\mathrm{C}_{10} \mathrm{H}_{14} \mathrm{~N}_{2} \mathrm{O}_{5}$ & 242. 23 & 0.406 \\
\hline 4 & AZT (Azidothymidine) & & $\mathrm{C}_{10} \mathrm{H}_{14} \mathrm{~N}_{5} \mathrm{O}_{4}$ & 268. 25 & 0.483 \\
\hline 5 & NPD8237 & & $\mathrm{C}_{16} \mathrm{H}_{18} \mathrm{~N}_{2} \mathrm{O}_{8} \mathrm{~S}$ & 398. 39 & 0.537 \\
\hline 6 & NPD13274 & & $\mathrm{C}_{18} \mathrm{H}_{21} \mathrm{FN}_{2} \mathrm{O}_{11}$ & 460.37 & 0.648 \\
\hline
\end{tabular}


Table I. Continued

\begin{tabular}{|c|c|c|c|c|c|}
\hline & Name & Structure & Formula & MW & Distance \\
\hline 7 & Polyoxin B & & $\mathrm{C}_{17} \mathrm{H}_{25} \mathrm{~N}_{5} \mathrm{O}_{13}$ & 507.41 & 0.666 \\
\hline 8 & Polyoxin D & & $\mathrm{C}_{17} \mathrm{H}_{23} \mathrm{~N}_{5} \mathrm{O}_{14}$ & 521.40 & 0.67 \\
\hline 9 & $\begin{array}{l}\text { NPD6561 (3-Deaza- } \\
\text { cytarabine) }\end{array}$ & & $\mathrm{C}_{10} \mathrm{H}_{14} \mathrm{~N}_{2} \mathrm{O}_{5}$ & 242. 23 & 0.679 \\
\hline 10 & 6-Azaur idine & & $\mathrm{C}_{8} \mathrm{H}_{11} \mathrm{~N}_{3} \mathrm{O}_{6}$ & 245. 19 & 0.688 \\
\hline 11 & NPD6666 & & $\mathrm{C}_{9} \mathrm{H}_{11} \mathrm{BrN}_{2} \mathrm{O}_{5}$ & 307. 10 & 0.692 \\
\hline
\end{tabular}

\section{Materials and Methods}

Reagents. BrUrd derivatives were kindly provided by RIKEN Natural Products Depository (NPDepo, Saitama, Japan). Chemical distances were determined by the Jaccard similarity index (11). Cytosine $\beta$-D-arabinofuranoside hydrochloride:cytarabine and gemcitabine hydrochloride were purchased from Sigma-Aldrich (St.Louis, MO, USA).

EdU incorporation assay. $4 \times 10^{4} \mathrm{HKe} 3$-wtKRAS cells and $1 \times 10^{4}$ HKe3-mtKRAS cells, which were established in an earlier study (10), were seeded in LabTek 8-chamber slides (Nunc, Rochester, NY, USA) for 2D culture or in a 96-well plate with an ultra-low attachment surface and a round bottom (Corning Inc., Corning, NY, USA) for $3 \mathrm{DF}$ culture at $37^{\circ} \mathrm{C}$ for three days. Cells were treated with EdU for an additional $16 \mathrm{~h}$. EdU was visualized using the Click-iT ${ }^{\mathrm{TM}}$ Plus EdU Imaging Kits Alexa (Life Technologies Corporation, Carlsbad, CA, USA) using the manufacturer's protocol.
Two-dimensional (2D) cell culture. HKe3-wtKRAS and HKe3mtKRAS cells were cultured in Dulbecco's modified Eagle's medium (DMEM)-high glucose (Life Technologies Corporation) supplemented with $10 \%$ fetal bovine serum, $1 \%$ penicillin/ streptomycin/Glutamine (Life Technologies Corporation), $600 \mu \mathrm{g} / \mathrm{ml}$ G418 (Wako, Osaka, Japan), and $2 \mu \mathrm{g} / \mathrm{ml}$ puromycin (Wako) as previously described $(10,12-19)$.

$3 D$ floating cell culture. HKe3-wtKRAS and HKe3-mtKRAS cells were seeded in 96-well plates with ultra-low attachment surfaces and round bottoms (Corning Inc.). Cells were cultured for 7 days in a $\mathrm{CO}_{2}$ incubator as previously described (10). Photomicrographs of cells were taken and analysed using an IN Cell Analyzer 1000 (GE Healthcare, Little Chalfont, UK) and IN Cell Developer Toolbox (GE Healthcare). The relative growth rate was calculated from a comparison of the area of control spheroids at day three.

Cell growth assay in 2D culture. $4 \times 10^{4} \mathrm{HKe} 3$-wtKRAS cells and $1 \times 10^{4} \mathrm{HKe} 3$-mtKRAS cells, which were established as previously 


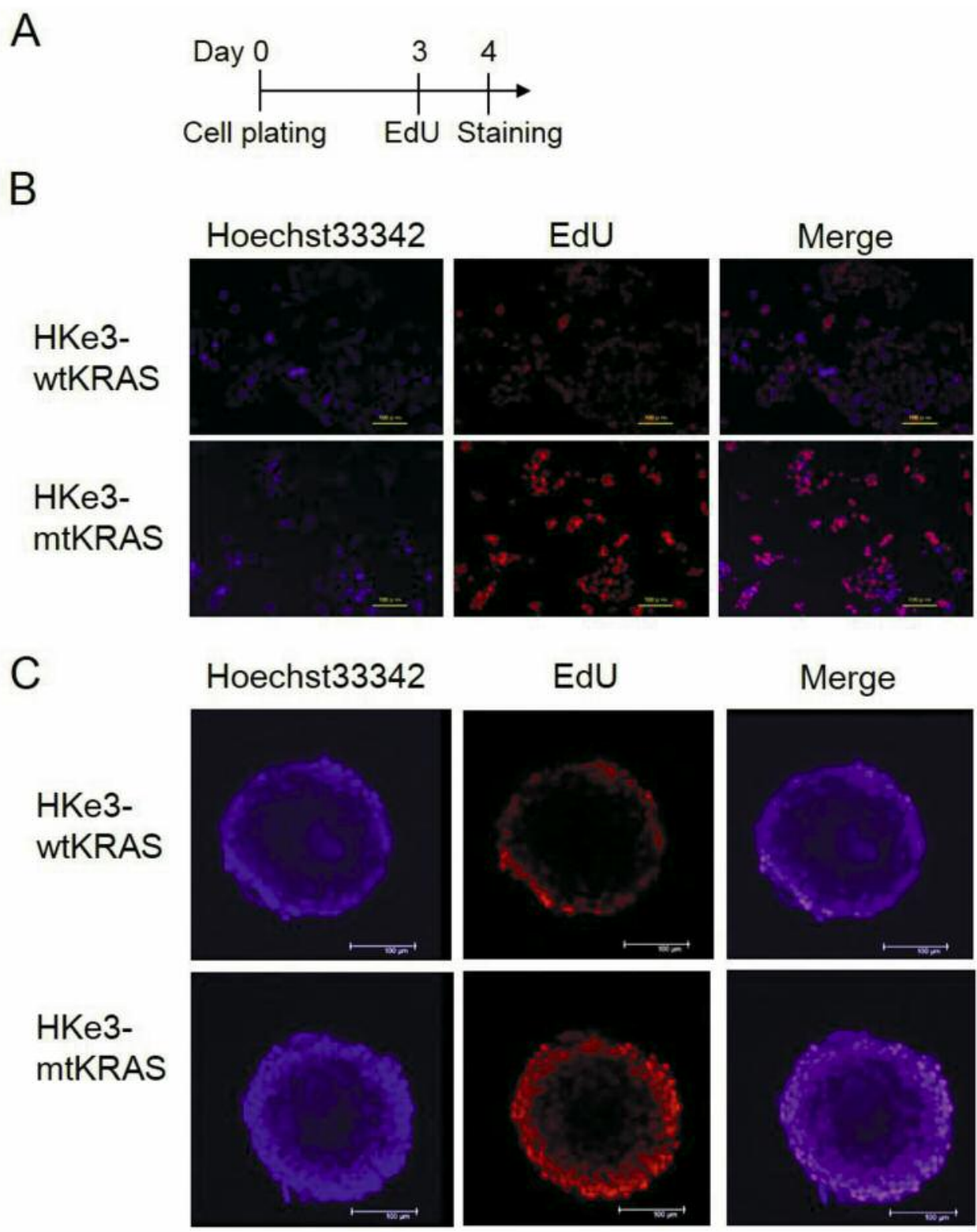

Figure 1. 5-Ethynyl-2'-deoxyuridine (EdU) incorporation in HKe3-wild type (wt) KRAS and HKe3-mutant (mt) KRAS cells grown in 2D and 3DF culture. A: Treatment scheme for EdU in $2 D$ and $3 D F$ culture. B, C: Left, middle and right panels: The signals for hoechst33342 (blue), EdU (red) and merged (merge) in HKe3-wtHKe3 (upper panels) and HKe3-mtHKe3 cells (lower panels) treated with EdU in $2 D(B)$ and $3 D F(C)$ culture, respectively. Scale bar $=100 \mu \mathrm{m}$.

described (10), were seeded in 96-well microplates (Corning) at $37^{\circ} \mathrm{C}$ for six days, and the absorbance of formazan solutions was measured using a 3-(4,5-dimethlthiazol-2-yl)-2,5-diphenyltetrazolium bromide (MTT) assay-based Cell Counting Kit-8 (Dojindo, Kumamoto, Japan) according to the supplier's instructions. The relative growth rate was calculated from a comparison of the absorbance obtained from cells treated with dimethyl sulfoxide (DMSO) alone as a vehicle control.

Statistical analyses. All experiments were performed in triplicate. Data are presented as means \pm standard deviations. Statistical analyses were performed using unpaired two-tailed Student's $t$-test in Microsoft Excel. $p$-Values of less than 0.05 were considered statistically significant.

\section{Results}

EdU incorporation in HKe3-wtKRAS and HKe3-mtKRAS cells grown in $2 D$ and $3 D F$ cultures. During the first screening, the uridine analogue, BrUrd, was identified as a 

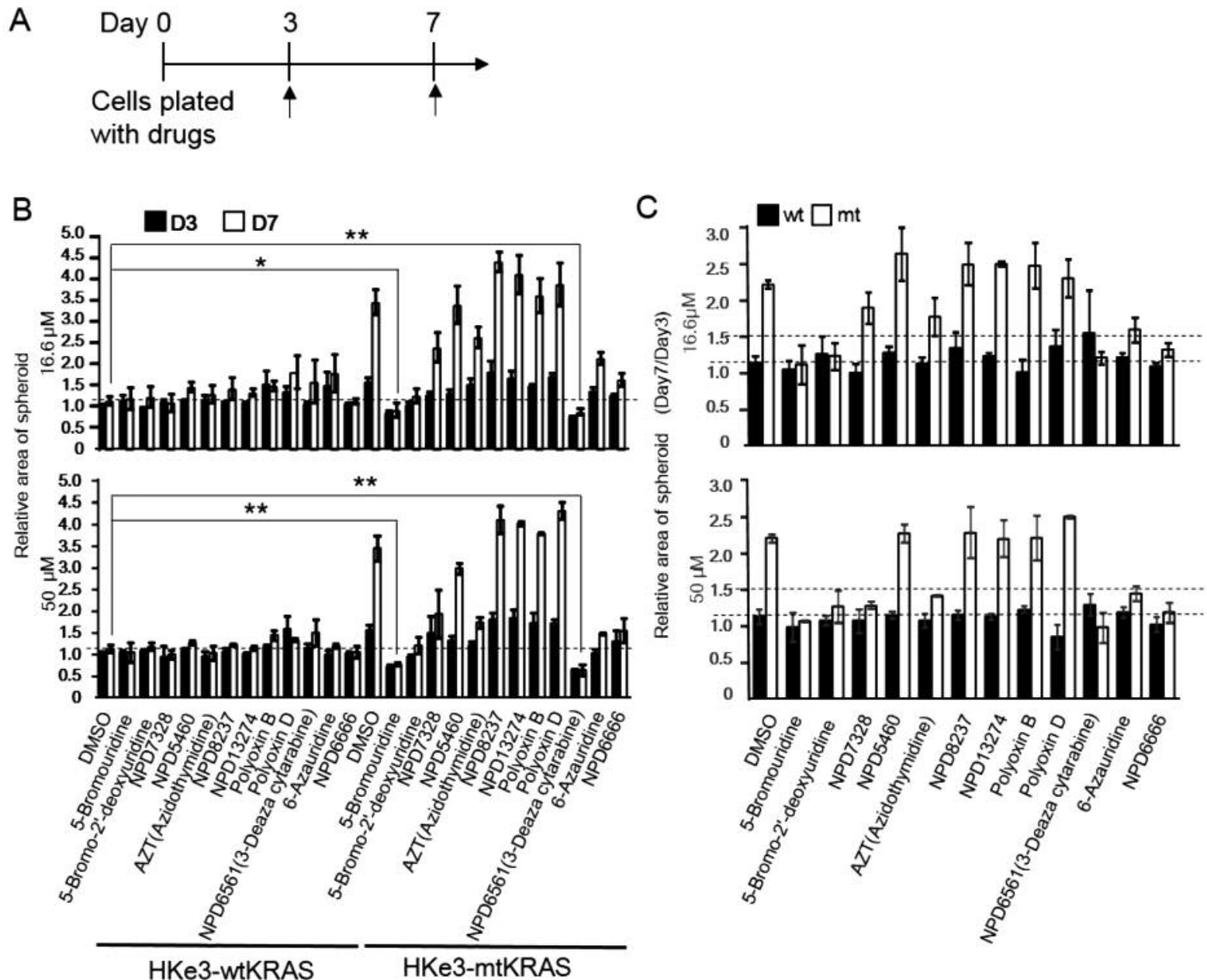

Figure 2. 5-Bromouridine (BrUrd) derivatives inhibit growth of HKe3-mutant (mt) KRAS spheroids. A: Treatment scheme for BrUrd derivatives in three-dimensional floating $(3 D F)$ culture. Arrow represents the measurement of the area of spheroids. B: Relative area of spheroids for HKe3-wild type (wt) KRAS and HKe3-mtKRAS with BrUrd derivatives at day 3 and day 7 against that for HKe3-wtKRAS with dimethyl sulfoxide (DMSO) control at day 3. ${ }^{*}<0.05 . * * p<0.01$. C: Relative area of spheroids for HKe3-wtKRAS and HKe3-mtKRAS with DMSO control and BrUrd derivatives at day 7 against that at day 3 , respectively.

candidate drug that inhibits the growth of HKe3-mtKRAS spheroids but not HKe3-wtKRAS spheroids (data not shown). A total of 11 BrUrd derivatives were selected from 4000 RIKEN libraries of natural products using chemical distance (11) (Table I). To address the hypothesis that BrUrd derivatives would be more strongly incorporated into HKe3mtKRAS cells to suppress the growth of tumour cells than HKe3-wtKRAS cells in 2D and 3DF cultures, EdU was used, another uridine analogue, to visualize DNA incorporation. Cells were plated at day 0 and treated with EdU overnight at day 3. EdU staining was performed at day 4 (Figure 1A). EdU was more strongly incorporated into HKe3-mtKRAS cells than HKe3-wtKRAS cells in 2D (Figure 1B) and 3DF (Figure 1C) cultures under the same experimental conditions, suggesting BrUrd derivatives, including uridine analogues may be selectively incorporated into tumours with mtKRAS and suppress tumour growth.

BrUrd derivatives inhibit the growth of HKe3-mtKRAS spheroids. To examine the effects of BrUrd derivatives on cell proliferation, cells were treated with 11 BrUrd derivatives or DMSO alone in $3 \mathrm{DF}$ culture. To make the volume of HKe3-wtKRAS spheroids and HKe3-mtKRAS spheroids at day 3 uniform, $4 \times 10^{4} \mathrm{HKe} 3$-wtKRAS cells and $1 \times 10^{4} \mathrm{HKe} 3$-mtKRAS cells were plated and the area of spheroids was measured at days 3 and 7 (Figure 2A). The scoring method shown in Table II was also established. The area of HKe3-mtKRAS spheroids with $16.6 \mu \mathrm{M}$ and 
Table II. Scoring method.

\begin{tabular}{|c|c|c|c|c|c|c|c|c|}
\hline \multirow[t]{2}{*}{$\begin{array}{l}\text { Chemical name or } \\
\text { NPD No. }\end{array}$} & M.W. & A & B & $\mathrm{C}$ & D & E & $\mathrm{F}$ & $\begin{array}{c}\mathrm{G}=\mathrm{A}+\mathrm{B}+\mathrm{C} \\
+\mathrm{D}+\mathrm{E}+\mathrm{F}\end{array}$ \\
\hline & & $\begin{array}{l}\text { The area of } \\
\text { HKe3-mtKRAS } \\
\text { spheroids with } \\
16.6 \mu \mathrm{M} \text { drugs } \\
\text { is decreased } \\
\text { (2p) compared } \\
\text { to that of } \\
\text { HKe3-wtKRAS } \\
\text { spheroids with } \\
\text { DMSO control } \\
\text { at day } 7 \text { or } \\
\text { decreased (1p) } \\
\text { or unchanged } \\
\text { (0p) compared } \\
\text { to that of } \\
\text { HKe3-mtKRAS } \\
\text { spheroids } \\
\text { with DMSO } \\
\text { control at day7 }\end{array}$ & $\begin{array}{c}\text { The area of HKe3- } \\
\text { mtKRAS } \\
\text { spheroids with } \\
50.0 \mu \mathrm{M} \text { drugs } \\
\text { is decreased } \\
\text { (2p) compared } \\
\text { to that of } \\
\text { HKe3-mtKRAS } \\
\text { spheroids with } \\
\text { DMSO control } \\
\text { at day } 7 \text { or } \\
\text { decreased (1p) or } \\
\text { unchanged (0p) } \\
\text { compared to } \\
\text { that of HKe3- } \\
\text { mtKRAS spheroids } \\
\text { with DMSO } \\
\text { control at day } 7\end{array}$ & $\begin{array}{c}\text { The increased } \\
\text { ratio of } \\
\text { HKe3-mtKRAS } \\
\text { with } 16.6 \mu \mathrm{M} \\
\text { drugs from } \\
\text { Day3 to day7. } \\
1.5 \text { fold< } \\
\text { increase: } \\
0 \mathrm{p}, 1.1 \sim 1.5 \text { fold } \\
\text { increase: } 1 \mathrm{p} \\
0 \sim 1.1 \text { fold } \\
\text { increase: } 2 \mathrm{p}\end{array}$ & $\begin{array}{c}\text { The increased } \\
\text { ratio of } \\
\text { HKe3-mtKRAS } \\
\text { with } 50.0 \mu \mathrm{M} \\
\text { drugs from } \\
\text { Day3 to day7. } \\
1.5 \text { fold< } \\
\text { increase: } \\
0 \mathrm{p}, 1.1 \sim 1.5 \text { fold } \\
\text { increase: } 1 \mathrm{p} \\
0 \sim 1.1 \text { fold } \\
\text { increase: } 2 \mathrm{p}\end{array}$ & $\begin{array}{l}\text { The increased } \\
\text { ratio of } \\
\text { HKe3-wtKRAS } \\
\text { with } 16.6 \mu \mathrm{M} \\
\text { drugs from } \\
\text { Day3 to day7. } \\
1.5 \text { fold< } \\
\text { increase: } 2 \mathrm{p}, \\
1.1 \sim 1.5 \text { fold } \\
\text { increase: } 1 \mathrm{p} \\
0 \sim 1.1 \text { fold } \\
\text { increase: } 0 \mathrm{p}\end{array}$ & $\begin{array}{c}\text { The increased } \\
\text { ratio of } \\
\text { HKe3-wtKRAS } \\
\text { with } 50.0 \mu \mathrm{M} \\
\text { drugs from } \\
\text { Day3 to day7. } \\
1.5 \text { fold< } \\
\text { increase: } 2 \mathrm{p}, \\
1.1 \sim 1.5 \text { fold } \\
\text { increase: } 1 \mathrm{p} \\
0 \sim 1.1 \text { fold } \\
\text { increase: } 0 \mathrm{p}\end{array}$ & Total:12p \\
\hline
\end{tabular}

\begin{tabular}{|c|c|c|c|c|c|c|c|c|}
\hline $\begin{array}{l}\text { 5-Bromouridine } \\
\text { (NPD5776) }\end{array}$ & 323.1 & 2 & 2 & 2 & 2 & 0 & 0 & 8 \\
\hline \multicolumn{9}{|l|}{$\begin{array}{l}\text { 5-Bromo-2'- } \\
\text { deoxyuridine }\end{array}$} \\
\hline (FSL0291) & 307.1 & 1 & 1 & 1 & 1 & 1 & 0 & 5 \\
\hline NPD7328 & 246.19 & 1 & 1 & 0 & 1 & 0 & 0 & 3 \\
\hline NPD5460 & 242.23 & 0 & 1 & 0 & 0 & 1 & 0 & 2 \\
\hline \multicolumn{9}{|l|}{ AZT(Azidothy- } \\
\hline midine)(FSL0381) & 268.25 & 1 & 1 & 0 & 1 & 0 & 0 & 3 \\
\hline NPD8237 & 398.39 & 0 & 0 & 0 & 0 & 1 & 1 & 2 \\
\hline NPD13274 & 460.37 & 0 & 0 & 0 & 0 & 1 & 1 & 2 \\
\hline Polyoxin B & 507.41 & 0 & 0 & 0 & 0 & 0 & 1 & 1 \\
\hline \multicolumn{9}{|l|}{ Polyoxin D } \\
\hline (FSL0806) & 521.39 & 0 & 0 & 0 & 0 & 1 & 0 & 1 \\
\hline \multicolumn{9}{|l|}{ NPD6561 (3- } \\
\hline Deaza-cytarabine) & 242.23 & 2 & 2 & 1 & 2 & 2 & 1 & 10 \\
\hline \multicolumn{9}{|l|}{ 6-Azauridine } \\
\hline (FSL0296) & 245.19 & 1 & 1 & 0 & 1 & 1 & 1 & 5 \\
\hline NPD6666 & 307.1 & 1 & 1 & 1 & 2 & 0 & 0 & 5 \\
\hline
\end{tabular}

$50.0 \mu \mathrm{M}$ of BrUrd at day 7 were 0.81 -fold $(p=0.049)$ and 0.76 -fold $(p=0.0023)$ compared to control and were respectively smaller in comparison to those of the $\mathrm{HKe} 3$ wtKRAS spheroids treated with DMSO alone at day 7 (Figure 2B). The area of HKe3-mtKRAS spheroids with 16.6 $\mu \mathrm{M}$ and $50.0 \mu \mathrm{M}$ of 3-deaza-cytarabine at day 7 were 0.76 fold $(p=0.0038)$ and 0.56 -fold $(p=0.0009)$ smaller in comparison to that of HKe3-wtKRAS spheroids treated with DMSO alone at day 7 , respectively (Figure 2B). These results suggest that 3-deaza-cytarabine suppresses spheroid growth more than BrUrd at the concentration of $16.6 \mu \mathrm{M}$. To test the late effect of these drugs from day 3 to day 7 , the area of HKe3-wtKRAS and -mtKRAS spheroids with $16.6 \mu \mathrm{M}$ and $50.0 \mu \mathrm{M}$ of BrUrd derivatives at day 7 were compared to that at day 3 (Figure 2C). The area of HKe3wtKRAS and HKe3-mtKRAS spheroids with DMSO at day 7, were 1.13-fold and 3.45-fold larger than the HKe3wtKRAS spheroids at day 3, respectively (Figure 2B and C). Among the BrUrd derivatives showing significant $(p<0.05)$ suppression of growth of HKe3-mtKRAS spheroids compared to those with DMSO control (3.45), the increased ratio with $16.6 \mu \mathrm{M}$ of $\mathrm{BrUrd}$, 5-Bromo-2'-deoxyuridine (BrdU), NPD7328, azidothymidine (AZT), 3-deaza cytarabine, 6-azauridine and NPD6666 from day 3 to day 7 
was $1.10,1.23,1.89,1.76,1.20,1.59$, and 1.31-fold (Figure $2 \mathrm{C})$, respectively, while the efficacy of $50.0 \mu \mathrm{M}$ was 1.07 , $1.27,1.28,1.42,0.98,1.45$ and 1.19-fold greater (Figure 2C). These results suggest that BrUrd (1.07) and 3-deazacytarabine $(0.98)$ at $50.0 \mu \mathrm{M}$ concentration showed greater efficacy for growth suppression than the other candidates. On the other hand, the increased ratio of HKe3-wtKRAS spheroids with $16.6 \mu \mathrm{M}$ and $50.0 \mu \mathrm{M}$ of BrUrd, 5-Bromo2'-deoxyuridine (BrdU), NPD7328, azidothymidine (AZT), 3-deaza cytarabine, 6-azauridine and NPD6666 from day 3 to day 7 was not significantly decreased compared to that with DMSO control. Notably, the increased ratio of HKe3wtKRAS with $50.0 \mu \mathrm{M}$ of 3-deaza-cytarabine was 1.14-fold larger than that with DMSO control (Figure 2C), suggestive of a low cytotoxicity of 3-deaza-cytarabine.

The efficacy of cytidine analogues for HKe3-wtKRAS and HKe3-mtKRAS cells grown in $2 D$ culture. Structurally, 3-deaza-cytarabine is similar with both uridine analogues and cytidine analogues. To compare the efficacy of 3-deazacytarabine with other cytidine analogues which are currently being used in clinical settings, including cytarabine and gemcitabine (2), the effect of cytarabine, 3-deaza-cytarabine and gemcitabine in 2D culture was first examined. Cells were plated at day 0 and treated with drugs from day 0 to day 6 (Figure 3A). An increase in the concentration of cytarabine from 0.1 to $5.0 \mu \mathrm{M}$ did not cause any statistically significant differences in cell proliferation of HKe3-wtKRAS and -mtKRAS cells in 2D culture (Figure 3B). While culturing cells with 3-deaza-cytarabine and gemcitabine show growth suppression of both HKe3-wtKRAS and mtKRAS cells in 2D culture (Figure $3 \mathrm{C}$ and D). These results suggest that the growth suppression of 3-deaza cytarabine and gemcitabine is stronger than that of cytarabine in HKe3-wtKRAS and -mtKRAS cells in 2D culture. The $0.1 \mu \mathrm{M}$ concentration of 3-deaza-cytarabine did not show any effect on cell proliferation (Figure 3C), however, the $0.1 \mu \mathrm{M}$ of gemcitabine significantly decreased proliferation of both HKe3-wtKRAS and -mtKRAS cells in 2DC (Figure 3D), suggesting that the cytotoxicity of gemcitabine is higher than that of 3-deaza-cytarabine.

The long-term effect of BrdU, 3-deaza-cytarabine, and gemcitabine for HKe3-wtKRAS and-mtKRAS spheroids. To determine the cytotoxicity of pyrimidine (uridine and cytidine) analogues, including BrdU, 3-deaza-cytarabine and gemcitabine with low concentrations of drugs during long term exposure, a long-term 3DF culture was performed. Cells were plated at day 0 and treated with drugs in serial dilutions and the area of spheroids was measured every three to four days until day 27 (Figure 4A). The area of HKe3wtKRAS spheroids with DMSO alone at day 27 was 2.48fold larger when compared to that at day 3 (Figure 4B). On
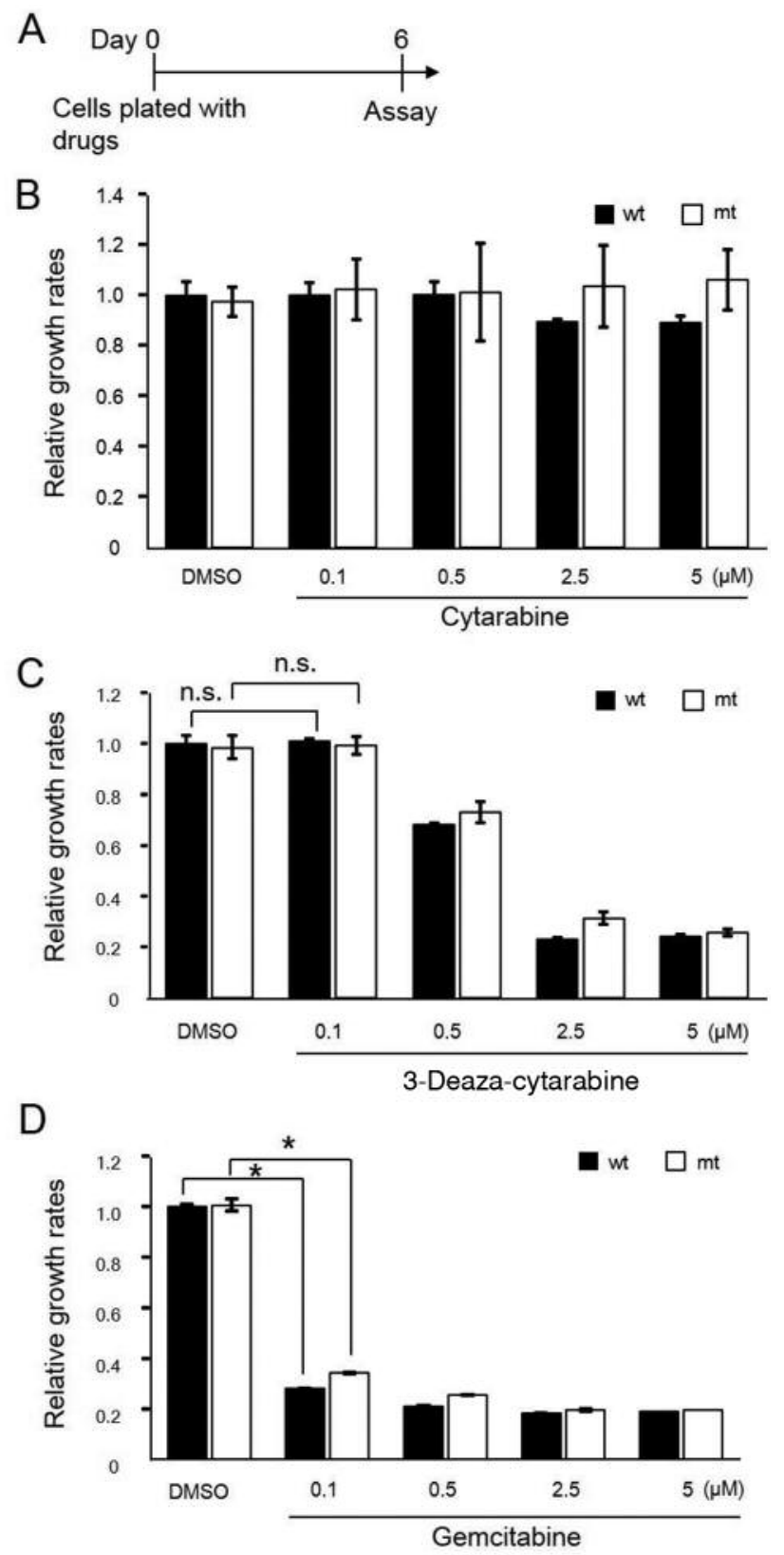

Figure 3. The effect of cytidine analogues for HKe3-wild type (wt) KRAS and HKe3-mutant (mt) KRAS cells grown in $2 D$ culture. A: Treatment scheme for cytarabine, 3-deaza-cytarabine, and gemcitabine in $2 D$ culture. B, C and D: Relative growth rates of HKe3-wtKRAS and HKe3mtKRAS with cytarabine (B), 3-deaza cytarabine $(C)$ and Gemcitabine (D) treatment in $3 D F$ culture at day $6 .{ }^{*} p<0.05$. n.s.: Not significant.

the other hand, the area of HKe3-mtKRAS spheroids with DMSO alone at day 27 were 15.75 -fold larger when compared to that at day 3 (Figure 4B). Treatment of HKe3mtKRAS spheroids by serially-diluted 3-deaza-cytarabine showed that the concentration required to achieve a $50 \%$ of 
A

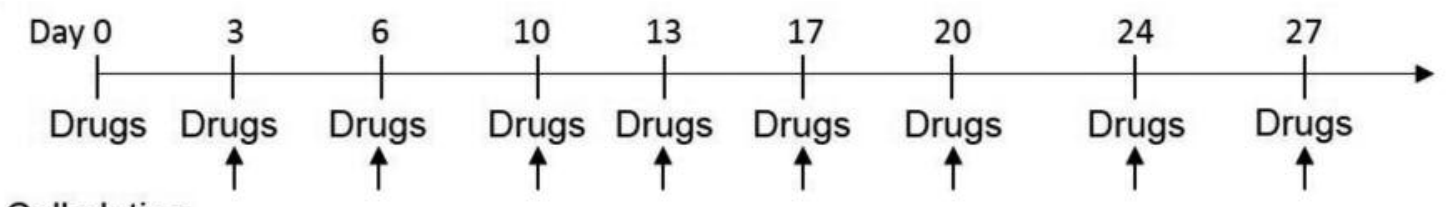

Cell plating
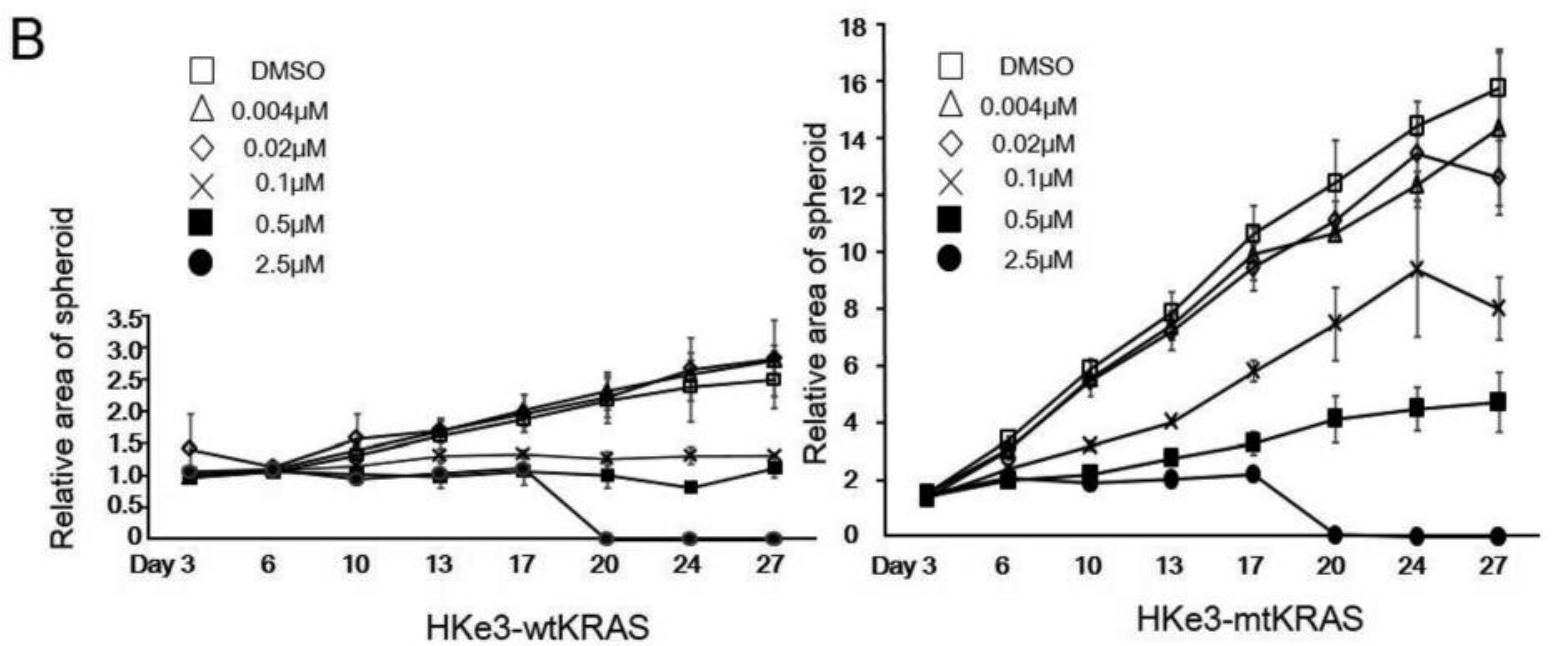

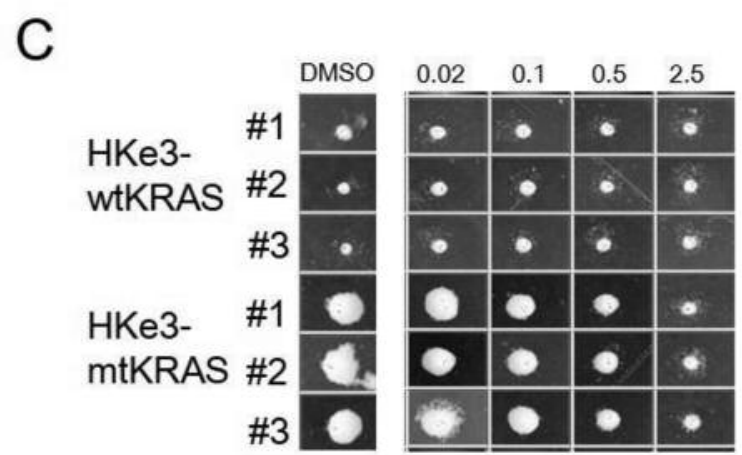

Brdu

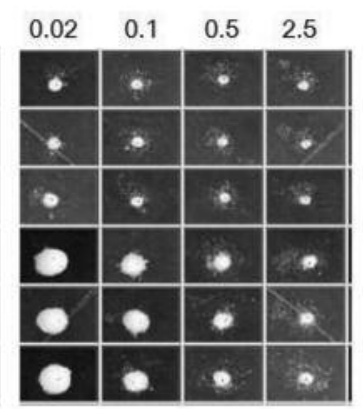

3-Deaza-

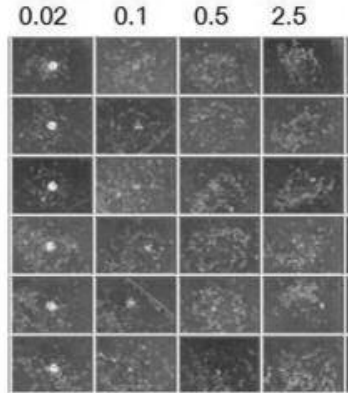

Gemcitabine

Figure 4. The long-term effect of 5-Bromo-2'-deoxyuridine (BrdU), 3-deaza cytarabine, and Gemcitabine for HKe3-wild type (wt) KRAS and -mutant (mt) KRAS spheroids. A: Treatment scheme for 5-Brdu, 3-deaza cytarabine, and gemcitabine in 3DF culture. Arrow represents the measurement of the area of spheroids. B: Relative area of spheroids for HKe3-wtKRAS (left panel) and HKe3-mtKRAS (right panel) spheroids with 3-deaza cytarabine from day 3 to day 27 against that for HKe3-wtKRAS with dimethyl sulfoxide (DMSO) control at day 3. C: Pictures of spheroids (\#1 \#3) for HKe3-wtKRAS (upper panel) and HKe3-mtKRAS (lower panel) spheroids with DMSO, BrdU (left panel), 3-deaza cytarabine (middle panel), and gemcitabine (right panel) at day 17.

the maximal inhibition in cell proliferation is approximately $0.5 \mu \mathrm{M}$ (Figure 4B). The area of HKe3-wtKRAS spheroids with BrdU and 3-deaza-cytarabine at day 17 is similar with DMSO control (Figure 4C), suggesting that both drugs do not display cytotoxicity to cells with wtKRAS. On the other hand, cytotoxicity of gemcitabine was observed in both
HKe3-wtKRAS and -mtKRAS spheroids at a concentration of $0.1 \mu \mathrm{M}$. Furthermore, the area of HKe3-mtKRAS spheroids with 0.1 and $0.5 \mu \mathrm{M}$ of BrdU was larger than that of 3-deaza-cytarabine at day 17 (Figure 4C), suggesting that the cytotoxicity of 3-deaza-cytarabine is stronger than that of BrdU. 


\section{Discussion}

In this study, it was demonstrated for the first time that BrUrd derivatives selectively reduce the growth of CRC spheroids with mtKRAS. In particular, the structure of 3-deazacytarabine is similar to both BrUrd and cytarabine (Table I). The uracil of BrUrd and the cytosine of cytarabine are similar in structure and both BrUrd and 3-deaza-cytarabine have arabinose as the sugar component which is thought to be the part that is incorporated into the DNA. Because 3-deazacytarabine lacks a nitrogen at the position 3 of the cytosine of cytarabine, 3-deaza-cytarabine correctly belongs to 3-deazacytidine analogue. Since, 3-deaza uridine has been demonstrated to have significant antitumor activity (20), 3deaza-cytarabine may also possess strong antitumor properties.

BrUrd, EdU and BrdU have been reported to be used for measuring DNA incorporation $(21,22)$. Recent work also suggested that these uridine analogues may play a role in the strong suppression of cancer cell proliferation (23-25). Notably, the uridine analogue, EdU was more strongly incorporated into newly synthesized DNA from Hke3mtKRAS cells than from HKe3-wtKRAS cells in 2D and $3 \mathrm{DF}$ cultures (Figure 1). From the view of structural similarities between BrUrd and 3-deaza-cytarabine (Table I), both analogues may selectively suppress the growth of mtKRAS tumours via the acceleration of DNA incorporation.

3-Deaza-cytarabine belongs to a set of cytidine analogues which include cytarabine and gemcitabine. Growth suppression by 3-deaza-cytarabine is stronger than cytarabine in $2 \mathrm{D}$ culture (Figure 3B) and its cytotoxicity is lower than gemcitabine in long-term 3DF culture (Figure 4C). Because the growth of HKe3-mtKRAS spheroids represent in vivo CRC growth and HKe3-wtKRAS spheroids represent the growth of normal colonic crypts in vivo (14), the selective suppression of 3-deazacytarabine for HKe3-mtKRAS spheroids indicates the utility of 3-deaza-cytarabine as an anticancer agent with low toxicity for tumours with mtKRAS. Furthermore, the suppressive effect of cytarabine is reported to be very weak for solid tumors (26) and the clinical use of gemcitabine is often limited due to primary/acquired drug resistance (27). Therefore, there is still room to further develop/improve novel nucleoside analogues used for the treatment of cancer patients with mtKRAS.

Using our culture system and scoring method (Table II), other compounds have already been identified in our lab showing selective effects for tumours with mtKRAS in 3D microenvironments and having different structures to BrUrd (data not shown).

\section{Acknowledgements}

The Authors thank Takami Danno, Yuriko Isoyama and Yumiko Hirose for their technical assistance. This study was supported by the Ministry of Education, Culture, Sports, Science and Technology of Japan.

\section{References}

1 Jordheim LP, Durantel D, Zoulim F and Dumontet C: Advances in the development of nucleoside and nucleotide analogues for cancer and viral diseases. Nat Rev Drug Discov 12: 447-464, 2013.

2 Galmarini CM, Mackey JR and Dumontet C: Nucleoside analogues and nucleobases in cancer treatment. Lancet Oncol 3: 415-424, 2002.

3 Chu MY and Fischer GA: A proposed mechanism of action of 1-beta-D-arabinofuranosyl-cytosine as an inhibitor of the growth of leukemic cells. Biochem Pharmacol 11: 423-430, 1962.

4 Heinemann V, Hertel LW, Grindey GB and Plunkett W: Comparison of the cellular pharmacokinetics and toxicity of 2',2'-difluorodeoxycytidine and 1-beta-D-arabinofuranosylcytosine. Cancer Res 48: 4024-4031, 1988.

5 Hertel LW, Boder GB, Kroin JS, Rinzel SM, Poore GA, Todd GC and Grindey GB: Evaluation of the antitumor activity of gemcitabine (2',2'-difluoro-2'-deoxycytidine). Cancer Res 50: 4417-4422, 1990.

6 Abbruzzese JL, Grunewald R, Weeks EA, Gravel D, Adams T, Nowak B, Mineishi S, Tarassoff P, Satterlee W, Raber MN et al: A phase I clinical, plasma, and cellular pharmacology study of gemcitabine. J Clin Oncol 9: 491-498, 1991.

7 Simanshu DK, Nissley DV and McCormick F: RAS Proteins and Their Regulators in Human Disease. Cell 170: 17-33, 2017.

8 Kim ST, Lim DH, Jang KT, Lim T, Lee J, Choi YL, Jang HL, Yi JH, Baek KK, Park SH, Park YS, Lim HY, Kang WK and Park JO: Impact of KRAS mutations on clinical outcomes in pancreatic cancer patients treated with first-line gemcitabinebased chemotherapy. Mol Cancer Ther 10: 1993-1999, 2011.

9 Karapetis CS, Khambata-Ford S, Jonker DJ, O'Callaghan CJ, Tu D, Tebbutt NC, Simes RJ, Chalchal H, Shapiro JD, Robitaille S, Price TJ, Shepherd L, Au HJ, Langer C, Moore MJ and Zalcberg JR: K-ras mutations and benefit from cetuximab in advanced colorectal cancer. N Engl J Med 359: 1757-1765, 2008.

10 Tsunoda T, Ishikura S, Doi K, Iwaihara Y, Hidesima H, Luo H, Hirose $\mathrm{Y}$ and Shirasawa S: Establishment of a Threedimensional Floating Cell Culture System for Screening Drugs Targeting KRAS-mediated Signaling Molecules. Anticancer Res 35: 4453-4459, 2015.

11 Levandowsky M and Winter D: Distance between Sets. Nature 234: 34, 1971.

12 Shirasawa S, Furuse M, Yokoyama N and Sasazuki T: Altered growth of human colon cancer cell lines disrupted at activated Ki-ras. Science 260: 85-88, 1993.

13 Baba I, Shirasawa S, Iwamoto R, Okumura K, Tsunoda T, Nishioka M, Fukuyama K, Yamamoto K, Mekada E and Sasazuki $\mathrm{T}$ : Involvement of deregulated epiregulin expression in tumorigenesis in vivo through activated Ki-Ras signaling pathway in human colon cancer cells. Cancer Res 60: 6886-6889, 2000.

14 Tsunoda T, Takashima Y, Fujimoto T, Koyanagi M, Yoshida Y, Doi K, Tanaka Y, Kuroki M, Sasazuki T and Shirasawa S: Threedimensionally specific inhibition of DNA repair-related genes by activated KRAS in colon crypt model. Neoplasia 12: 397-404, 2010 .

15 Tsunoda T, Takashima Y, Yoshida Y, Doi K, Tanaka Y, Fujimoto T, Machida T, Ota T, Koyanagi M, Kuroki M, Sasazuki T and Shirasawa S: Oncogenic KRAS regulates miR-200c and miR221/222 in a 3D-specific manner in colorectal cancer cells. Anticancer Res 31: 2453-2459, 2011. 
16 Ota T, Doi K, Fujimoto T, Tanaka Y, Ogawa M, Matsuzaki H, Kuroki M, Miyamoto S, Shirasawa S and Tsunoda T: KRAS upregulates the expression of miR-181a, miR-200c and miR-210 in a three-dimensional-specific manner in DLD-1 colorectal cancer cells. Anticancer Res 32: 2271-2275, 2012.

17 Yoshida Y, Tsunoda T, Doi K, Fujimoto T, Tanaka Y, Ota T, Ogawa M, Matsuzaki H, Kuroki M, Iwasaki A and Shirasawa S: ALPK2 is crucial for luminal apoptosis and DNA repair-related gene expression in a three-dimensional colonic-crypt model. Anticancer Res 32: 2301-2308, 2012.

18 Yoshida Y, Tsunoda T, Doi K, Tanaka Y, Fujimoto T, Machida T, Ota T, Koyanagi M, Takashima Y, Sasazuki T, Kuroki M, Iwasaki A and Shirasawa S: KRAS-mediated up-regulation of RRM2 expression is essential for the proliferation of colorectal cancer cell lines. Anticancer Res 31: 2535-2539, 2011.

19 Tsunoda T, Furusato B, Takashima Y, Ravulapalli S, Dobi A, Srivastava S, McLeod DG, Sesterhenn IA, Ornstein DK and Shirasawa S: The increased expression of periostin during early stages of prostate cancer and advanced stages of cancer stroma. Prostate 69: 1398-1403, 2009.

20 Moriconi WJ, Slavik M and Taylor S: 3-Deazauridine (NSC 126849): an interesting modulator of biochemical response. Invest New Drugs 4: 67-84, 1986.

21 Jensen PO, Larsen J, Christiansen J and Larsen JK: Flow cytometric measurement of RNA synthesis using bromouridine labelling and bromodeoxyuridine antibodies. Cytometry 14: 455458, 1993.

22 Salic A and Mitchison TJ: A chemical method for fast and sensitive detection of DNA synthesis in vivo. Proc Natl Acad Sci USA 105: 2415-2420, 2008.
23 Levkoff LH, Marshall GP, 2nd, Ross HH, Caldeira M, Reynolds BA, Cakiroglu M, Mariani CL, Streit WJ and Laywell ED: Bromodeoxyuridine inhibits cancer cell proliferation in vitro and in vivo. Neoplasia 10: 804-816, 2008.

24 Ross HH, Rahman M, Levkoff LH, Millette S, Martin-Carreras T, Dunbar EM, Reynolds BA and Laywell ED: Ethynyldeoxyuridine (EdU) suppresses in vitro population expansion and in vivo tumor progression of human glioblastoma cells. J Neurooncol 105: 485498, 2011.

25 Li X, Patel R, Melamed MR and Darzynkiewicz Z: The cell cycle effects and induction of apoptosis by 5-bromouridine in cultures of human leukaemic MOLT-4 and HL-60 cell lines and mitogen-stimulated normal lymphocytes. Cell Prolif 27: 307319, 1994.

26 Koo HM, Monks A, Mikheev A, Rubinstein LV, Gray-Goodrich M, McWilliams MJ, Alvord WG, Oie HK, Gazdar AF, Paull KD, Zarbl H and Vande Woude GF: Enhanced sensitivity to 1-betaD-arabinofuranosylcytosine and topoisomerase II inhibitors in tumor cell lines harboring activated ras oncogenes. Cancer Res 56: 5211-5216, 1996.

27 Amrutkar M and Gladhaug IP: pancreatic cancer chemoresistance to gemcitabine. Cancers (Basel) 9: pii: E157, 2017. 